\title{
Single-dose cefotaxime intramuscularly cures gonococcal ophthalmia neonatorum
}

\author{
PHILIPPE LEPAGE,' JOS BOGAERTS,' PHILIPPE KESTELYN,' \\ AND ANDRÉ MEHEUS ${ }^{2}$
}

From the 'Departments of Paediatrics, Microbiology, and Ophthalmology, Kigali Hospital, BP 879, Kigali, Rwanda, and the ${ }^{2}$ World Health Organisation, Programme Manager, Sexually Transmitted Diseases, Geneva

SUMMARY Nine neonates with culture proved gonococcal ophthalmia neonatorum were treated with a single intramuscular injection of $100 \mathrm{mg} / \mathrm{kg}$ of cefotaxime without topical antibiotic therapy. Five of the nine strains were penicillinase-producing Neisseria gonorrhoeae. All nine cases were clinically and microbiologically cured, and no side effects were observed.

Gonococcal ophthalmia neonatorum ceased to be a public health problem once silver nitrate ocular prophylaxis was systematically introduced early this century. In industrialised countries the condition lost its blinding character in the 1940 s when penicillin became generally available.

With the emergence and spread of penicillinaseproducing Neisseria gonorrhoeae (PPNG) strains since $1976^{1}$ other antibiotics such as the third generation cephalosporins and kanamycin were introduced for the treatment of these infections. ${ }^{2-5}$ The prevalence of PPNG strains remains low in industrialised countries, but in the developing world, in particular in South-east Asia and Africa, they account for up to 20 to $80 \%$ of circulating gonococcal strains. ${ }^{6}$ Hence gonococcal ophthalmia neonatorum may again become a blinding disease in these parts of the world unless effective and simple treatment schedules are available.

This study reports the results of treating gonococcal ophthalmia neonatorum with a single dose of cefotaxime $100 \mathrm{mg} / \mathrm{kg}$ intramuscularly.

\section{Material and methods}

Cases of gonococcal ophthalmia neonatorum seen at the paediatric outpatient department of Kigali Hospital, Rwanda, Central Africa, during the year 1985 are included in this study.

In neonates with purulent conjunctivitis a presumptive clinical diagnosis was confirmed by Gram stain and culture for $N$. gonorrhoeae on modified Correspondence to Dr Philippe Lepage.
Thayer-Martin medium. All nine cases included had a positive culture, and all strains were tested for $\beta$-lactamase production by the chromogenic cephalosporin test. Three cases were referred from peripheral health units and had received antibiotic therapy.

The patients were treated with a single intramuscular injection of cefotaxime $100 \mathrm{mg} / \mathrm{kg}$, without topical antibiotics. Mothers received a single dose of spectinomycin $2 \mathrm{~g}$ intramuscularly as epidemiological treatment.

The infants were examined by an ophthalmologist (KP) before and after treatment to monitor eventual corneal complications. A follow-up examination was planned for 3 and 7 days after the day of treatment, and conjunctival swabs were taken for control cultures.

\section{Results}

Characteristics of the nine patients and results of antimicrobial therapy are summarised in Table 1. Their ages ranged from 2 to 36 days with a median age ? of 9 days. Four infants were male and five female. All the patients presented with a purulent ocular discharge, which was bilateral in seven of the nine. One presented with gonococcal ophthalmia neonatorum and a purulent otitis media; cefotaxime treatment was continued for five days in this case.

Five out of the nine isolates proved to be PPNG strains. All nine patients were clinically cured without any residual eye damage. Moreover, all followup cultures were negative for $N$. gonorrhoeae. 
Table 1 Gonococcal ophthalmia neonatorum treated with cefotaxime $100 \mathrm{mg} / \mathrm{kg}$ single dose intramuscularly: characteristics of patients and treatment results

\begin{tabular}{|c|c|c|c|c|c|c|c|c|}
\hline \multirow[t]{2}{*}{ Case } & \multirow{2}{*}{$\underset{\text { (days) }}{\text { Age }}$} & \multirow[t]{2}{*}{$\operatorname{Sex}$} & \multirow{2}{*}{$\begin{array}{l}\text { Weight } \\
(\mathrm{kg})\end{array}$} & \multirow{2}{*}{$\begin{array}{l}\text { Clinical } \\
\text { features }\end{array}$} & \multirow[t]{2}{*}{ Previous therapy } & \multirow[t]{2}{*}{$\beta$-lactamase } & \multicolumn{2}{|l|}{ Follow-up } \\
\hline & & & & & & & Clinical & ure \\
\hline 1 & 13 & $\mathbf{F}$ & $3 \cdot 4$ & Bilat. & - & - & Cured (day 3) & Neg. (day 3) \\
\hline 2 & 13 & $\mathbf{F}$ & $2 \cdot 3$ & Bilat. & Penicillin IM for 6 days & + & Cured (day 2 and 7 ) & Neg. (day 7) \\
\hline 3 & 2 & $\mathbf{F}$ & 1.6 & Bilat. & - & + & Cured (day 2, 5 and 7) & Neg. (day 2 and 7 ) \\
\hline 4 & 7 & $\mathbf{M}$ & $2 \cdot 0$ & Bilat.* & $\begin{array}{l}\text { Penicillin IM for } 4 \text { days }+ \\
\text { chloromycetin eye ointment }\end{array}$ & + & Cured (day 4 and 6) & Neg. (day 6) \\
\hline 5 & 8 & $\mathbf{F}$ & $3 \cdot 3$ & Unilat. & - & + & Cured (day 4,7 , and 11 ) & Neg. (day 4 and 7 ) \\
\hline 6 & 17 & $\mathbf{M}$ & $2 \cdot 8$ & Bilat. & Tetracycline eye ointment & - & Cured (day 3) & Neg. (day 3 ) \\
\hline 7 & 36 & $\mathbf{M}$ & $3 \cdot 4$ & Bilat. & - & - & Cured (day 4) & Neg. (day 4) \\
\hline 8 & 9 & $\mathbf{M}$ & $2 \cdot 9$ & Bilat. & - & + & Cured (day 3 and 8 ) & Neg. (day 8) \\
\hline 9 & 11 & $\mathbf{F}$ & $3 \cdot 15$ & Unilat. & - & - & Cured (day 5) & Not done \\
\hline
\end{tabular}

*Plus right purulent otitis media (culture negative on day 0 ); received cefotaxime $100 \mathrm{mg} / \mathrm{kg} / \mathrm{day}$ intramuscularly in two doses for five days.

\section{Discussion}

These data show that cefotaxime in a single intramuscular injection of $100 \mathrm{mg} / \mathrm{kg}$ without topical antibiotic therapy effectively cures gonococcal ophthalmia neonatorum due to PPNG and nonPPNG strains.

It has been demonstrated that gonococcal ophthalmia neonatorum should be treated by systemic antibiotics either alone or in combination with local treatment, but not by local therapy alone. ${ }^{7}$ Until recently penicillin was the treatment of choice worldwide, and a schedule of aqueous benzylpenicillin, 50000 units $/ \mathrm{kg} /$ day given intravenously in two doses for seven days with admission of the neonate to hospital was recommended. ${ }^{8}$

Following the emergence of PPNG strains cases of gonococcal ophthalmia neonatorum due to these strains have been reported. So long as the prevalence of PPNG infections remains low, and provided very close supervision of the newborn babies' eyes is possible, it is still acceptable to initiate therapy with penicillin. These conditions are not met within developing countries: strict medical supervision is often impossible, and the prevalence of PPNG strains among circulating gonococci is above $20 \%$ in most countries. In Rwanda $52 \%$ of gonococcal isolates are PPNG strains, and of the non-PPNG strains $26 \%$ are chromosomally resistant to penicillin. ${ }^{9}$

Penicillin treatment is inappropriate in such circumstances, and if one wants to prevent blindness as a complication of gonococcal ophthalmia neonatorum highly effective antibiotic treatment has to be instituted from the start.

Treatment by a single dose presents a great advantage over multidose schedules, as does a regimen without eye ointment or drops. Local therapy to the eyes of the newborn is difficult in poor conditions, has low compliance, and may itself cause infections.

Single-dose intramuscular kanamycin if combined with a topical antibiotic for three days has been shown to be effective in gonococcal ophthalmia neonatorum due to PPNG and non-PPNG strains. ${ }^{45}$ But although ototoxicity is unlikely with single-dose kanamycin therapy the potential for it makes it difficult to recommend the regimen as a first choice. Cefotaxime or gentamicin has been recommended for gonococcal ophthalmia neonatorum due to PPNG. ${ }^{8}$ A case report showed that cefotaxime 100 $\mathrm{mg} / \mathrm{kg} /$ day for seven days was effective. ${ }^{2}$ As the third generation cephalosporins were shown to be highly effective in single-dose treatment of gonococcal infections in adults, ${ }^{111}$ their effectiveness in gonococcal ophthalmia neonatorum could be expected. A single intramuscular dose of $125 \mathrm{mg}$ of ceftriaxone was reported to have been effective in seven cases, ${ }^{3}$ and the present study shows excellent results with a single-dose of cefotaxime.

A working group of the World Health Organisation recommended the addition of tetracycline ointment $1 \%$ for 10 days to a single intramuscular injection of $100 \mathrm{mg} / \mathrm{kg}$ of cefotaxime. ${ }^{12}$ Our study proves that additional topical antibiotherapy is not required. Lower doses of cefotaxime, for instance a single intramuscular injection of $50 \mathrm{mg} / \mathrm{kg}$, are probably as effective and should be studied further.

\section{References}

1 World Health Organisation. Surveillance of $\beta$-lactamaseproducing N. gonorrhoeae (PPNG). Weekly Epidem Rec 1983; 2: 5-7.

2 Doraiswamy B, Hammerschlag MR, Pringle GF, du Bouchet L. Ophthalmia neonatorum caused by $\beta$-lactamase-producing Neisseria gonorrhoeae. JAMA 1983; 250: 790-1.

3 Haase DA, Nash RA, Nsanze H, et al. Single-dose ceftriaxone 
therapy of gonococcal ophthalmia neonatorum. Sex Transm Dis 1986; 13: 53-5.

4 Thirumoorthy T, Rajan VS, Goh CL. Penicillinase-producing Neisseria gonorrhoeae ophthalmia neonatorum in Singapore. Br J Vener Dis 1982; 58: 308-10.

5 Fransen L, Nsanze H, Ronald AR, Piot P, D'Costa L, Brunham R. Single-dose kanamycin therapy of gonococcal ophthalmia neonatorum. Lancet 1984; ii: 1234-7.

6 Osoba AO. Overview of penicillinase producing Neisseria gonorrhoeae in Africa. Afr J Sex Transm Dis 1986; 2: 51-5.

7 Rajan VS, Pang R, Sng EH. An evaluation of treatment in gonococcal ophthalmia neonatorum. Singapore Med J 1978; 19 $86-8$.
8 Sexually transmitted diseases. Treatment guidelines, 1982. MMWR 1982; 31 (suppl): 33S-60S.

9 Bogaerts J, Vandepitte J, Van Dyck E, Vanhoof R, Dekegel M, Piot $\mathrm{P}$. In vitro antimicrobial sensitivity of Neisseria gonorrhoeae from Rwanda. Genitourin Med 1986; 62: 217-20.

10 Handsfield $\mathrm{HH}$, Holmes KK. Treatment of uncomplicated gonorrhea with cefotaxime. Sex Transm Dis 1981; 8: 187-91.

11 Handsfield HH, Murphy VL. Comparative study of ceftriaxone and spectinomycin for treatment for uncomplicated gonorrhoea in men. Lancet 1983; ii: 67-70.

12 World Health Organisation. Conjunctivitis of the newbornprevention and treatment at the primary health care level. Geneva World Health Organisation, 1986.

Accepted for publication 4 March 1988. 